\title{
RANCANG BANGUN MONITORING DAN PENYIMPANAN NILAI DAYA LISTRIK SECARA REAL TIME PADA BASIS DATA
}

I Dewa Gde Bayu Wiranatha ${ }^{1}$, Cok Gede Indra Partha ${ }^{2}$, Widyadi Setiawan ${ }^{3}$

Program Studi Teknik Elektro, Fakultas Teknik, Universitas Udayana, Badung - Bali Email : bayuwira14@gmai.com, cokindra@unud.ac.id, widyadi@unud.ac.id

\begin{abstract}
ABSTRAK
Manajemen hotel melakukan pemantauan energi untuk mengetahui konsumsi energi listrik pada hotel tersebut. Pemantauan energi dilakukan guna tercapainyaa penggunaan energi listrik yang efisien, unutk melakukan pemantauan energi secara akurat dibutuhkan sebuah alat yang mampu memantau pemakaian daya secara real time dan menyimpan pada media digital atau database sehingga mudah untuk diakses. Data yang disimpan pada database menggunakan bantuan mikrokontroler dan Ethernet Shiled yang terhubung dengan jaringan LAN. Sensor yang digunkan pada penelitian ini berupa trafosmator tegangan (step down) 220VAC:9VAC dan sensor arus dengan kapasitas arus maksimal $100 \mathrm{~A}$. Hasil dari perekaman data adalah penyimpangan sensor arus tertinggi $2,4 \%$ dan penyimpangan sensor tegangan tertinggi adalah $0,4 \%$.
\end{abstract}

Kata Kunci : Mikrokontroler, Sensor, Basis Data, LAN.

\section{ABSTRACT}

Hotel management to monitor the energy to know the electrical energy consumption at the hotel. Energy monitoring is carried out in order to achieve the efficient use of electrical energy, for accurate energy monitoring requires a tool that can monitor the power consumption in real time and store on digital media or database so easy to access. Data stored on the database using the help of microcontroller and Ethernet Shiled connected to the LAN network. The sensors used in this research are voltage down 220VAC: 9VAC and current sensors with maximum current capacity of $100 \mathrm{~A}$. The result of data recording is the highest current sensor deviation of $2.4 \%$ and the highest voltage sensor deviation is $0.4 \%$.

Key Word : Microcontroller, Sensor, Database, LAN

\section{PENDAHULUAN}

Perusahaan yang bergerak dibidang perhotelan merupakan salah satu jenis jasa akomodasi pariwisata. Hotel memiliki biaya oprasional untuk pemakaian energi listrik yang sangat besar, hal ini tidak terlepas d ari tiap kamar pada hotel banyak terdapat perlatan elektronik seperti pendingin ruangan(air conditioner), televisi, pengiring rambut, dan kulkas untuk memanjakan para tamu yang menginap dihotel tersebut. Pulau Bali yang menjadikan pariwisata sebagai komoditas utama perekonimian masyarakatnya tentunya memiliki jumlah bangunan hotel yang terus meningkat sejalan dengan kenaikan wisatawan domestik maupun mancanegara.

Kepala BPS (Badan Pusat Statistik) Provinsi Bali, Adi Nugroho, mengatakan pertumbuhan hotel dan kamar hotel di Bali sangat

pesat.Pada tahun 2006 hotel bintang di Bali berjumlah 147 hotel, namun pada tahun 2015 telah terjadi peningkatan mencapai 281 hotel bintang, sedangkan secara keseluruhan baik hotel bintang maupun non bintang mencapai 2.079 hotel, padahal di tahun 2006 jumlahnya hanya 1.635 hotel. pada 2015 ini, jumlah hotel di Bali bertambah sebanyak 29 unit atau naik 1,14 persen dibandingkan tahun sebelumnya. Hotel berbintang bertambah sebanyak 32 unit atau lebih dari 12 persen [1].

Peningkatan jumlah hotel di Bali tentu juga harus dibarengi dengan penambahan jumlah daya listrik untuk memenuhi kebutuhan wisatawan baik lokal maupun mancanegara. Pembangunan pembangkit listrik baik konvensional, energi baru dan energi baru terbarukan (EBT) untuk memenuhi peningkatan 
kebutuhan listrik tentunya akan memakan waktu dan biaya yang cukup besar, alternatif lainya yang dapat dilakukan adalah manajemen hotel melakukan penghematan energi untuk mengefisiensi penggunaan energi listrik. Manajemen hotel memiliki kendala dalam melakukan pemantauan energi guna melakukan efisiensi secara akurat, untuk itu dibutuhkan sebuah alat yang mampu memantau pemakaian daya secara real time dan menyimpan pada media digital atau database, agar data hasil monitoring mudah untuk diakses.

\section{KAJIAN PUSTAKA}

\subsection{Mikrokontroler ATmega 328}

Mikrokontroler adalah salah satu dari bagian dasar dari suatu sistem komputer. Meskipun mempunyai bentuk yang jauh lebih kecil dari suatu komputer pribadi dan komputer mainframe, mikrokontroler dibangun dari komponen-komponen dasar yang sama, secara sederhana, komputer akan melakukan tugas yang telah diinputkan serta akan menghasilkan output spesifik sesuai yang telah terprogram sebelumnya. Seperti umumnya komputer, mikrokontroler adalah alat yang mengerjakan instruksi-instruksi yang diberikan kepadanya. Artinya, utama dari suatu sistem terkomputerisasi adalah program itu sendiri yang dibuat oleh seorang programmer. Program ini menginstruksikan komputer untuk melakukan jalinan yang panjang dari aksi-aksi sederhana untuk melakukan tugas yang lebih kompleks yang diinginkan oleh programmer [2].

Mikrokontroler ATmega 328 memiliki arsitektur Harvard, yaitu memisahkan memori untuk kode program dan memori untuk data sehingga dapat memaksimalkan kerja dan parallelism. Instruksi-instruksi dalam memori program dieksekusi dalam satu alur tunggal, dimana pada saat satu instruksi dikerjakan instruksi berikutnya sudah diambil dari memori program. Konsep inilah yang memungkinkan instruksi - instruksi dapat dieksekusi dalam setiap satu siklus clock [3]. Arduino Uno dapat dilihat pada Gambar 1 dengan mikrokontroler terpasang adalah ATmega 328.

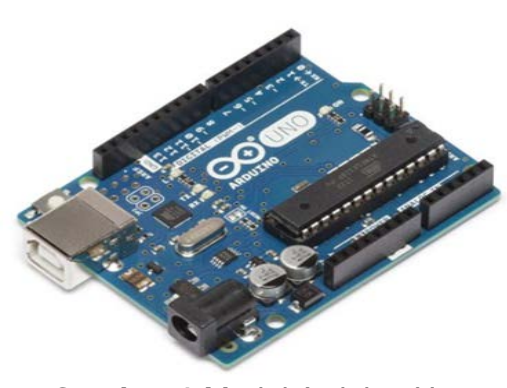

Gambar 1 Modul Arduino Uno

\subsection{Sensor Arus}

Teknologi sensor arus hampir sama dengan teknologi sensor tegangan yaitu dengan menggunakan trafo arus yang dikenal dengan Current Trafo (CT) dan dengan menggunakan teknologi efek hall. Dalam proses induksi, arus listrik yang melalui kawat sisi primer akan menghasilkan sebuah medan magnet pada inti ferrite CT sensor. Kawat pada sisi sekunder yang mengelilingi inti tersebut menghasilkan arus listrik kecil yang proporsional [4]. Sensor arus pada penelitian ini dapat dilihat pada Gambar 2. Pada penelitian ini digunakan 3 sensor arus dengan kemampuan ukur arus maksimal $100 \mathrm{~A}$.

\subsection{Sensor Tegangan}

Sensor tegangan yang digunakan dalam penelitian ini berupa pembagi tegangan dengan transformator penurun tegangan. Pada penerapanya sensor tegangan berupa suatu alat yang dikenal dengan $A C$ to $A C$ Power Adapter merupakan penurun tegangan rendah dari tegangan $\mathrm{AC}$ yang biasanya pada tegangan nominal 220 Volt pada satu phasa. Untuk menghindari bekerja langsung pada tegangan tinggi yang bisa merusak mikrokontroler yang akan digunakan pada sebuah alat.

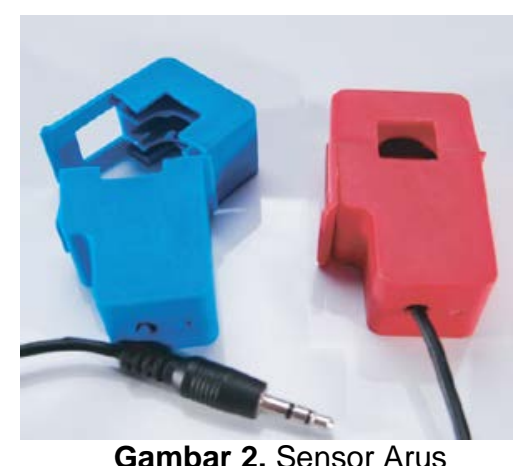


AC to AC Power Adapter akan mampu menurunkan tegangan nominal 220 Volt AC menjadi 9 hingga 12 Volt AC. Rangkaian pembagi tegangan biasanya digunakan untuk membuat suatu tegangan referensi dari sumber tegangan yang lebih besar, titik tegangan referensi pada sensor, untuk memberikan bias pada rangkaian penguat atau untuk memberi bias pada komponen aktif [4]. Pada penelitian ini digunakan hanya 1 sensor tegangan saja dengan asumsi setiap phasa memiliki tegangan yang sesuai dengan standar PLN yaitu + $5 \%$ dan $-10 \%$ dari tegangan nominal [5]

\subsection{Ethernet Shield Arduino}

Ethernet Shield merupakan perangkat tambahan yang digunakan untuk menghubungkan Arduino ke dalam jaringan komputer atau internet. Shield ini memakai WIZnet W5100 Ethernet Chip yang dapat memberi kemampuan untuk menjaadiakn Arduino dapat diakses secara online. Penggunaan Shield ini disertai library Arduino untuk menulis sketch. Chip WIZnet W5100 mampu hingga empat koneksi soket secara berbarengan. Dalam menggunakan perangkat ini cukup dengan menempatkan Shield di atas Arduino Uno yang ada untuk pemrogramannya cukup menghubungkan Arduino dengan komputer via USB sebagaimana memprogram Arduino seperti biasa, serta menghubungkan Ethernet Shield dengan komputer atau hub atau router, dapat menggunakan kabel UTP Cat5 dengan konektor RJ45[6].

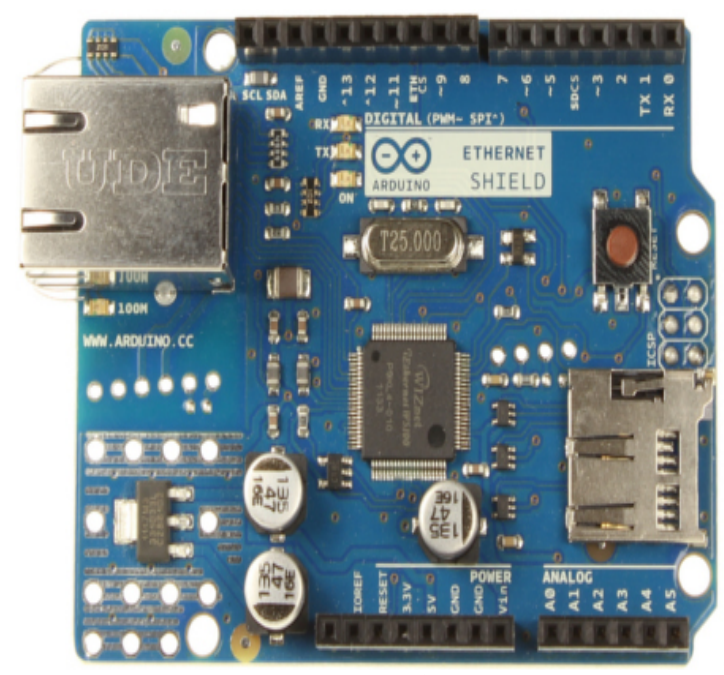

Gambar 3. Ethernet Shield Arduino

\subsection{Basis Data}

Basis data (database) adalah kumpulan data yang disimpan secara sistematis di dalam komputer yang dapat diolah atau dimanipulasi menggunakan perangkat lunak (program aplikasi) untuk menghasilkan informasi. Pendefinisian basis data meliputi spesifikasi berupa tipe data, struktur data dan juga batasan-batasan pada data yang akan disimpan. Basis data merupakan aspek yang sangat penting dalam sistem informasi karena berfungsi sebagai gudang penyimpanan data yang akan diolah lebih lanjut. Basis data menjadi penting karena dapat mengorganisasi data, menghidari duplikasi data, menghindari hubungan antar data yang tidak jelas dan juga update yang rumit [7].

DBMS merupakan sistem perangkat lunak yang memungkinkan pengguna basis data (database user) agar dapat memelihara, mengontrol dan mengakses data secara praktis dan efisien. dengan kata lain, semua akses ke basis data akan ditangani oleh DBMS. DBMS ini menjadi lapisan yang mengkoneksiakan basis data dengan program antar muka untuk memastikan bahwa basis data tetap ter-manage secara tetap dan dapat diakses dengan mudah [7]. Basis data pada penelitian ini adalah MySQL.

\section{METODE PENELITIAN}

Penelitian atau pembuatan alat dilakukan di Lab. Dasar Teknik Elektro, Program Studi Tekonik Elektro, Fakultas Teknik, Universitas Udayana, Bukit-Jimbaran. Jenis data yang digunakan dalam penelitian ini yaitu data premier yang berasal dari alat monitoring yang mencakup data arus, tegangan dan daya, serta data sekunder yang berasal dari buku, jurnal, dan literatur yang mendukung teori rancang bangun monitoring energi secara real time. Metode penelitian dalam penelitian ini adalah observasi atau pengamatan alat monitoring energi secara real time yang dirancang, dari hasil observasi akan dapat dilihat keakuratan alat dalam memonitoring energi listrik dengan membandingkanya dengan alat ukur yang sudah terstandarisasi.

\subsection{Rancangan Perangkat Lunak}

Tahap pembuatan perangkat lunak dilakukan pada dua aplikasi program yaitu 
pada IDE Arduino dan PHP 7.0. diagram alir pembuatan perancangan perangkat lunak dapat dilihat pada Gambar 4.
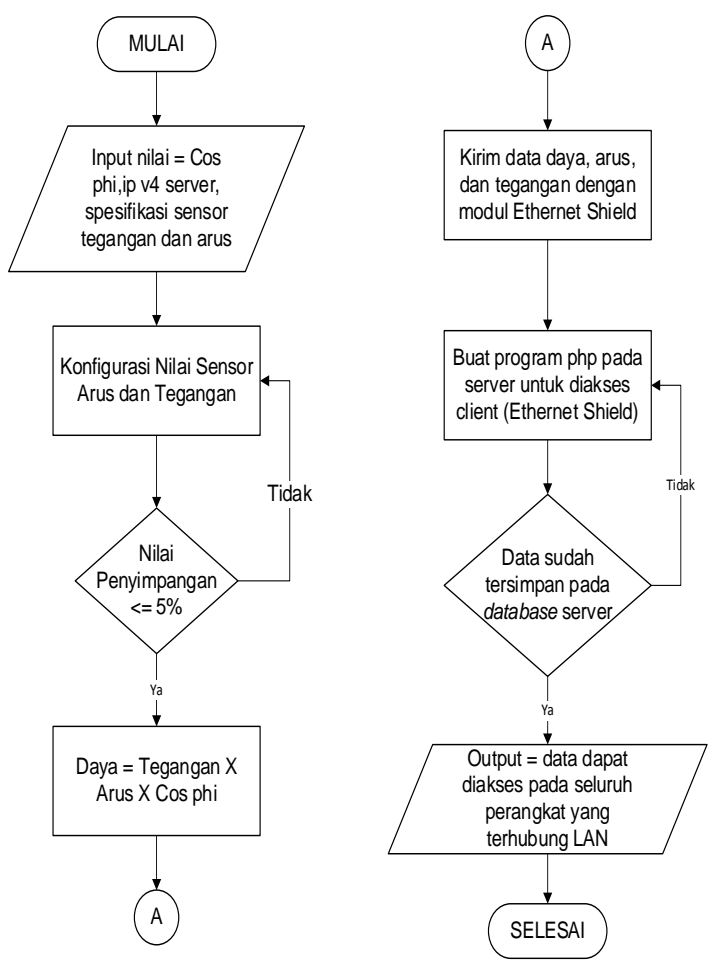

Gambar 4. Diagram Alir Perangkat Lunak

Penjelasan Diagram alir perangkat lunak dapat dijelaskan sebagai berikut :

1. Tahap pembuatan perangkat lunak dimulai dengan mendefinisiakan nilai-nilai yang dibutuhkan pada alat monitoring dan penyimpanan energi listrik secara real time seperti nilai $\cos \phi$, spesifikasi tahanan sensor arus, nilai trafo pembagi tegangan, nilai resistor pembagi tegangan, serta nomer Internet Protocol Server yang akan diakses Ethernet Shield. Data - data tersebut dimasukan ke dalam program IDE Arduino.

2. Kedua adalah membandingkan nilai arus dan tegangan yang terbaca oleh sensor yang terpasang pada alat dengan alat ukur yang sudah standar, jika perbedaan nilai pembacaan sensor dengan alat ukur standar masih lebih dari 5\% maka perlu dilakukan perubahan kembali pada parameter-pamrameter sensor arus dan tegangan hingga nilai pembacaan sensor mendekati nilai pembacaan alat ukur standar.
3. Tahap berikutnya adalah mengkaliakan nilai arus dengan tegangan untuk mendapatkan nilai daya yang terpakai. Data sensor arus, tegangan, dan daya akan terprogram untuk terkirim melalui ethernet shield ke server yang dituju.

4. Pada sisi server program PHP yang sudah berisi alamat server, nama database, user name dan password database, nama tabel pada database, serta data kolom yang akan disesuaikan dengan data-data yang akan dikirim dari ethernet shield.

5. Terakhir adalah data-data yang sudah tersimpan pada database dapat diakses pada semua perangkat yang terhubung dengan jaringan LAN yang sama dengan server serta mengetahui user name dan password untuk mekases database. Contoh pengerjaan program pada mikrokontroler dapat dilihat pada Gambar 5.

\subsection{Rancangan Perangkat Keras}

Pada Gambar 6 akan dijelaskan blok diagram kerja perangkat keras rancang bangun monitoring dan penyimpanan nilai daya listrik secara real time pada database, dengan peralatan adalah sensor arus YHCT$100 \mathrm{~A} / 1 \mathrm{~V}$, sensor tegangan yang terdiri dari transformator tengangan 220 VAC : 9 VAC I $1 \mathrm{~A}$ dan pembagi tegangan dengan dua

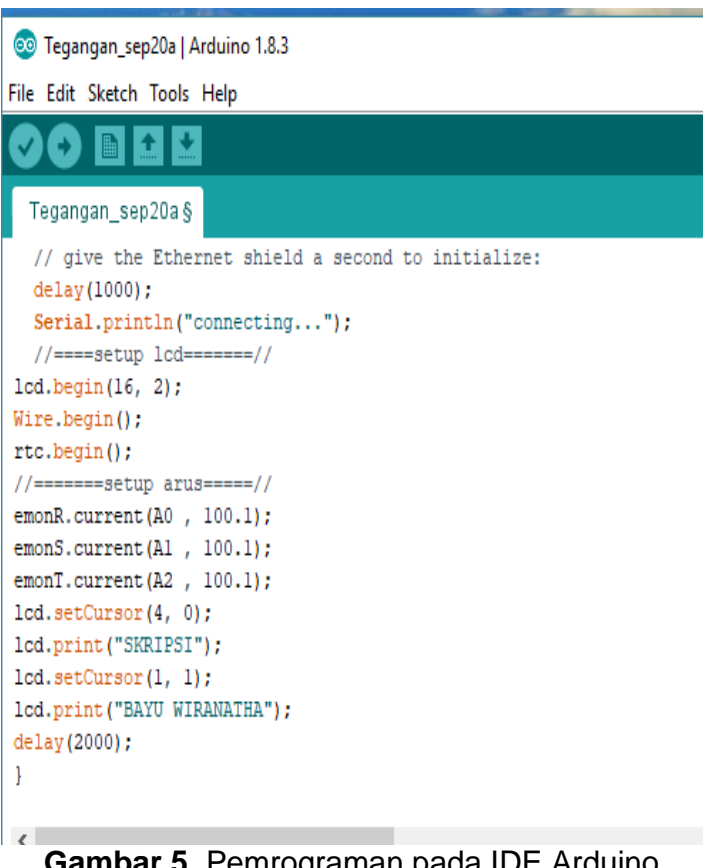

Gambar 5. Pemrograman pada IDE Arduino 


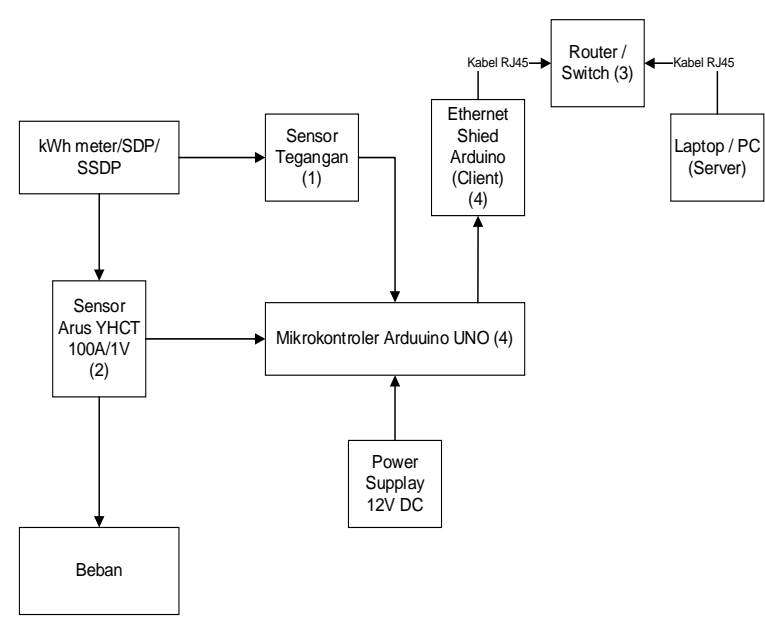

Gambar 6. Diagram Blok Perangkat Keras

resistor $10 \mathrm{k} \Omega$, mikrokontroler ATmega 328 yang sudah terpasang pada modul Arduino UNO, Ethernet shield dan komputer atau laptop yang sudah terkoneksi dengan jaringan LAN, serta Icd $16 \times 2$ sebagai display pada alat monitoring dan penyimpanan nilai daya secara real time pada basis data

Pada alat monitoring dan penyimpanan nilai daya secara real time pada database menggunakan catudaya 12 VDC sebagai supplay mikrokontroler ATmega 328, sedangkan fungsi dari mikrokontroler sendiri adalah untuk mengolah sinyal output dari sensor sensor arus dan tegangan dan mengolah data tersebut menjadi nilai arus dan tegangan nyata untuk selanjutnya dikirim dengan menggunakan modul ethernet shield ke dalam database. Router memiliki peran untuk memberikan akses LAN (Local Area Network) pada laptop dan rancan bangun monitoring dan penyimpanan nilai daya secara real time agar bisa saling berkomunikasi. Penomoran pada diagram blok perangkat keras Gambar 6 merujuk pada Gambar 7 tampak atas alat monitoring dan penyimpanan nilai daya secara real time

\section{HASIL DAN PEMBAHASAN}

4.1 Realisasi Rancang Bangun Monitoring dan Penyimpanan Nilai Daya Secara Real Time pada Database

Realisasi rancang bangun monitoring dan penyimpanan nilai daya secara real time pada database dapat dilihat pada Gambar 7,

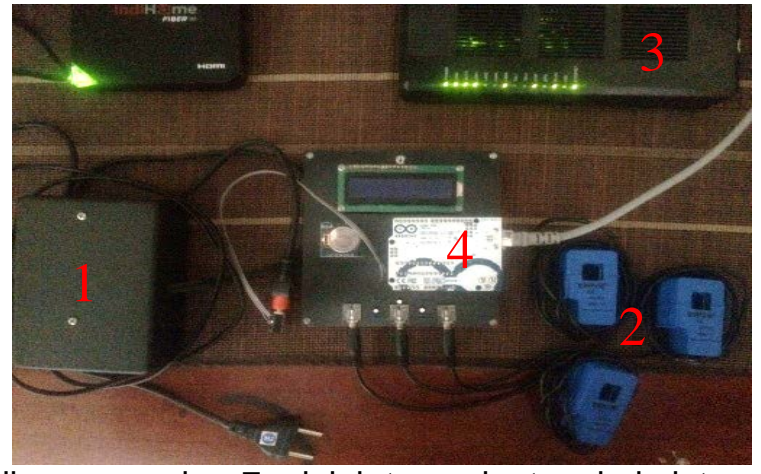

dimana gambar 7 adalah tampak atas dari alat monitoring dan penyimpanan nilai daya

Gambar 7. Tampak atas alat monitoring dan penyimpanan nilai daya secara real time

dimana Gambar 7 adalah tampak atas dari alat. Penomoran pada tampak atas alat monitoring dan penyimpanan nilai daya secara real time Gambar 7 merujuk pada Gambar 6 diagram blok perangkat keras

\subsection{Hasil dan Pembahasan Sensor Arus}

Pengujian dan pembahasan rangkain sensor arus bertujuan untuk mengetahui akurasi pembacaan sensor terhadap arus listrik yang mengalir pada beban yang diukur. Pada proses pengujian sensor perlu dilakukan kalibrasi agar nilai arus yang di baca oleh sensor arus sama dengan hasil pembacaan alat ukur seperti tang ampere. Hasil perbandingan antara sensor arus dengan alat ukur tang ampere dapat dilihat pada Tabel 1 dan Gambar 8.

Tabel 1. Presentase penyimpangan sensor arus

\begin{tabular}{|c|r|r|r|}
\hline No & $\begin{array}{c}\text { Hasil } \\
\text { Pembacaan } \\
\text { Sensor (A) }\end{array}$ & $\begin{array}{c}\text { Hasil } \\
\text { Pengukuran } \\
\text { Arus Tang } \\
\text { Ampere } \\
\text { Digital (A) }\end{array}$ & $\begin{array}{c}\text { Presentase } \\
\text { Penyimpang } \\
\text { an sensor } \\
\text { arus (\%) }\end{array}$ \\
\hline 1 & 2.99 & 3.03 & $1,3 \%$ \\
\hline 2 & 0,85 & 0,83 & $2,4 \%$ \\
\hline 3 & 0,56 & 0,55 & $1,8 \%$ \\
\hline
\end{tabular}

Hasil yang didapat dari 3 kali percobaan dalam membandingkan sensor arus dengan tang ampere digital adalah hasil pembacaan sensor yang terpasang pada alat ukur memiliki penyimpangan terbesar yaitu $2,4 \%$ dan terkecil adalah $1,3 \%$, maka dapat disimpulkan bawha sensor arus yang terpasang sudah siap digunakan dalam rancang bangun monitoring dan penyimpanan nilai daya listrik 
secara real time pada basis data. Keterangan nomor 1 pada Gambar 8 menunjukan alat ukur tang ampere digital, sedangkan nomor 2

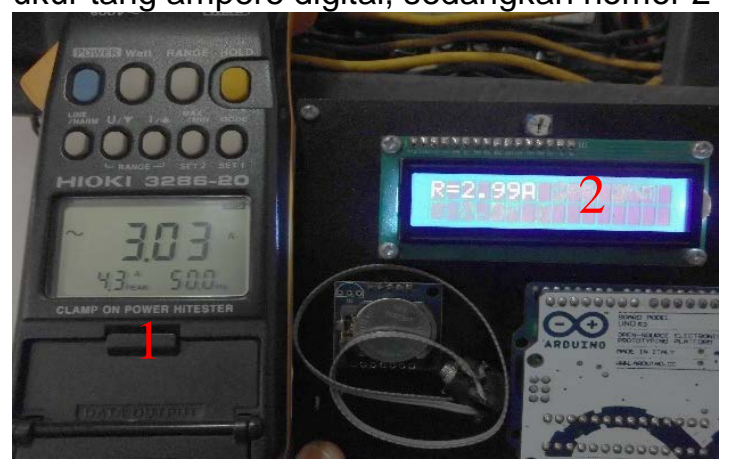

Gambar 8. Pengukuran sensor arus

menunjukan hasil pengukuran arus menggunakan sensor tegangan

\subsection{Hasil dan Pembahasan Sensor Tegangan}

Pengujian dan pembahasan rangkain sensor tegangan bertujuan untuk mengetahui akurasi pembacaan sensor terhadap tegangan yang mengalir pada beban yang diukur. Pada proses pengujian sensor perlu dilakukan kalibrasi agar nilai tegangan yang di baca oleh sensor tegangan sama dengan hasil pembacaan alat ukur seperti tang ampere. Hasil perbandingan antara sensor tegangan dengan alat ukur tang ampere dapat dilihat pada Tabel 2 dan Gambar 9.

Tabel 2. Presentase penyimpangan sensor tegangan

\begin{tabular}{|c|c|r|r|}
\hline No & \multicolumn{2}{|c|}{$\begin{array}{c}\text { Hasil Pembacaan } \\
\text { Tegangan }\end{array}$} & $\begin{array}{c}\text { Presentase } \\
\text { Penyimpangan } \\
\text { Sensor } \\
\text { Tegangan (\%) }\end{array}$ \\
\cline { 2 - 3 } & $\begin{array}{c}\text { Sensor } \\
\text { Tegangan } \\
\text { (Volt) }\end{array}$ & $\begin{array}{c}\text { Tang } \\
\text { Ampere } \\
\text { Digital (Volt) }\end{array}$ & \\
\hline 1 & 0,00 & 0,00 & $0,00 \%$ \\
\hline 2 & 141,00 & 140,40 & $0,42 \%$ \\
\hline 3 & 160,50 & 161,00 & $0,30 \%$ \\
\hline 4 & 180,00 & 180,30 & $0,30 \%$ \\
\hline 5 & 213,40 & 214,00 & $0,20 \%$ \\
\hline
\end{tabular}

Hasil yang didapat dari 5 kali percobaan dalam membandingkan sensor tegangan dengan tang ampere digital adalah hasil pembacaan sensor yang terpasang pada alat ukur memiliki penyimpangan terbesar yaitu 0,42 \% dan terkecil adalah 0\%, maka dapat disimpulkan bawha sensor arus yang terpasang sudah siap digunakan dalam rancang bangun monitoring dan penyimpanan nilai daya listrik secara real time pada basis data. Gambar 9. Pengukuran sensor tegangan

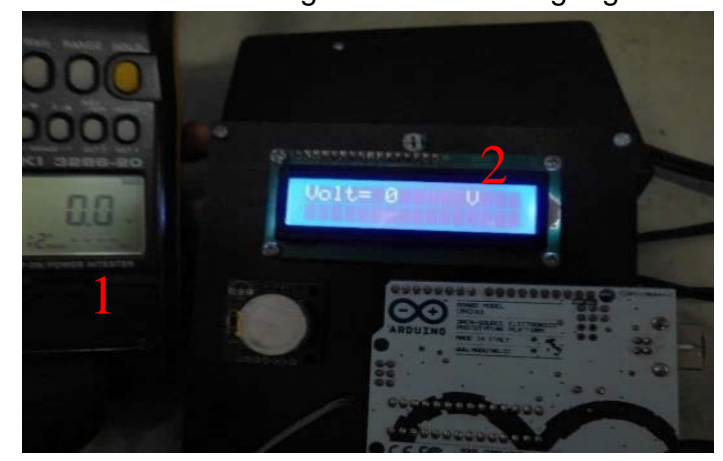

Keterangan nomor 1 pada Gambar 9 menunjukan alat ukur tang ampere digital, sedangkan nomor 2 menunjukan hasil pengukuran teganga menggunakan sensor tegangan

\subsection{Hasil dan Pembahasan Ethernet Shield}

Pengujian Ethernet Shield dilakukan dengan mengirimkan nilai analog pada pin $\mathrm{AO}$ sampai dengan A5 yang terdapat pada mikrokontroler 328 kedalam web melalui jaringan LAN, hal ini dilakukan untuk mengetahui kemampuan modul ethernet shield dalam berkomunikasi dengan perangkat lain seperti PC atau laptop yang terhubung dengan jaringan LAN yang sama. Hasil pengujian dari Ethernet Shield dapat dilihat pada Gambar 10.

Hasil pengujian Ethernet Shiled yang dilakukan dengan menguji kemampuan modul untuk mengirim dan menampilkan nilai dari pin analog Arduino kedalam browser dapat dikatakan berhasil dan siap digunakan dalam rancang bangun monitoring dan penyimpanan

\subsubsection{7}

analog input 0 is 704

analog input 1 is 513

analog input 2 is 349

analog input 3 is 85

analog input 4 is 1021

analog input 5 is 1022 
Gambar 10. Menampilkan Nilai Analog Mikrokontroler pada Browser

nilai daya listrik secara real time pada basis data, hal ini dapat dilihat pada Gambar 10 yaitu nilai analog dari pin-pin Arduino sudah dapat diakses melalui browser pada komputer ataupun laptop.

\subsection{Hasil dan Pembahasan Tampilan Data pada Basis Data}

Tahap memasukan data pada database MySQL dan ditampilkan pada browser dengan program phpMyadmin adalah dengan membuat database dan tabel baru yang akan ditujukan untuk menyimpan nilai-nilai yang terukur pada alat, selanjutnya membuat akun user dan password untuk mengkases database yang telah dibuat sebelumnya untuk tetap menjaga privasi data yang tersimpan, terakhir membuat program PHP yang nantinya akan diakses oleh modul Ethernet sebagai client berisikan nama database, nama tabel dalam database, user dan password account, IP address server, serta peletakan data sesuai urutan kolom pada tabel database. Pada Gambar 11 menunjukan keberhasilan monitoring dan penyimpanan data rancang bangun monitoring dan penyimpanan daya listrik secara real time pada basis data.

\section{Simpulan}

Simpulan yang didapat berdasarkan hasil pengujian rancang bangun monitoring dan penyimpanan nilai daya listrik secara real time pada basis data adalah

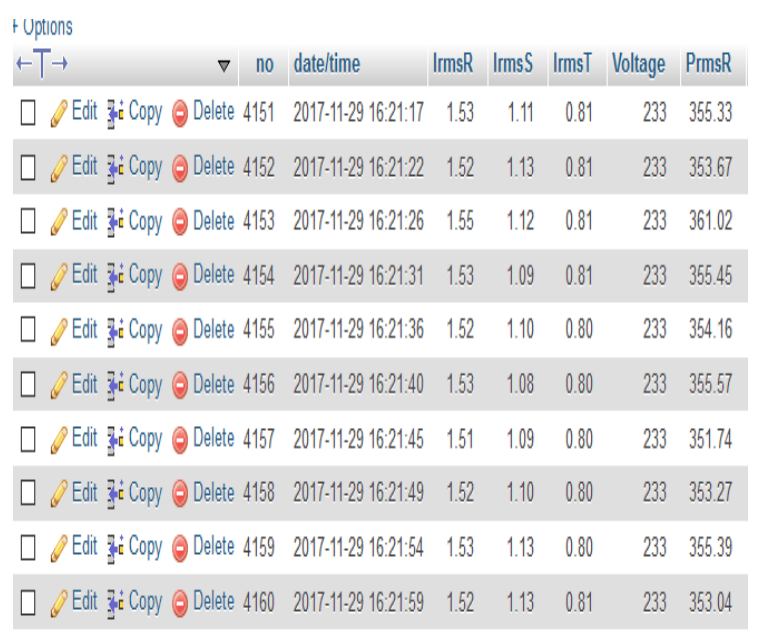

Gambar 11. Hasil Penyimpanan data pada database MySQL

1. Rancang bangun monitoring dan penyimpanan nilai daya listrik secara real time pada basis data berhasil direalisasikan dan terdiri atas beberapa komponen utama yaitu mikrokontroler ATmega 328 sebagai pengolah data, Liquid Crystal Display (LCD) sebagai tampilan data monitoring pada alat, sensor tegangan sebagai pembaca nilai tegangan dengan transformator step down (220AC:9VAC) dengan nilai penyimpangan terbesar adalah $0,42 \%$, sensor arus dengan CT terpasang 100A :1V sebagai pembaca nilai arus pada beban dengan nilai penyimpangan terbesar adalah 2,4\%, Ethernet Shield sebagai pengirim data dengan menggunkan jaringan LAN.

2. Nilai daya, arus, dan tegangan dapat disimpan dan ditampilkan secara digital dengan menggunakan basis data MySQL dan aplikasi penampilnya pada web atau browser yaitu phpMyAdmin guna mempermudah proses pencatatan daya listrik secara digital.

\section{Daftar Pustaka}

[1] http://bali.tribunnews.com /2017/04/20/jumlah-hotel-di-bali-naikjadi-2079disparda-dan-phri-usulkan moratorium?page=all. Diakses pada 14 Maret 2018.

[2] Sutanto,Hermawan.Konsep Mikrokonteroler.[Online] http://mikrokontroler.tripod.com/6805/ba b1.htm. Diakses pada 15 Maret 2018.

[3] "Data Sheet AVR Mikrokontroler 328/328P". Atmel, 2016.

[4] Dinatha, I., Sunanda, W. 2015. Implementasi Wireless Monitoring Energi Listrik Berbasis Web Database. J. Nasional Teknik Elektro., 4(1): 86-88.

[5] SPLN 1:1999, Ketentuan Variasi Tegangan, Hal 5.

[6] "Data Sheet Ethernet Shiled V1", Arduino.

[7] http://www.termasmedia.com/lainnya/software/69-pengertiandatabase.html,di akases pada 15 Maret 2018 